\title{
Are we prepared for clinical trials in Charcot-Marie-Tooth
}

\section{disease?}

Rossor AM" ${ }^{a}$, Shy $\mathrm{ME}^{\mathrm{b}}$, Reilly $\mathrm{MM}^{\mathrm{a}}$

a. Department of Neuromuscular Diseases, University College London Queen Square Institute of Neurology, London, United Kingdom.

b. Department of Neurology, University of lowa, 200 Hawkins Drive, lowa City, IA 52242, USA

Corresponding author:

Dr Alexander M Rossor

Email: a.rossor@ucl.ac.uk 


\section{Abstract}

There has been considerable progress in developing treatments for Charcot-Marie-Tooth disease with a number of therapies either completing or nearing clinical trials. In the case of CMT1A, the commonest subtype of CMT, there have been more than five randomised, double blind placebo-controlled trials. Although these trials were negative for the primary outcome measure, considerable lessons have been learnt leading to the collection of large prospective natural history data sets with which to inform future trial design as well as the development of new and sensitive outcome measures.

In this review we summarise the difficulties of conducting clinical trials in a slowly progressive disease such as CMT1A and the requirement for sensitive, reproducible and clinically relevant outcome measures. We summarise the current array of CMT specific outcome measures subdivided into clinical outcome measures, functional outcome measures, patient reported outcome measures, biomarkers of disease burden and treatment specific biomarkers of target engagement. Although there is now an array of CMT specific outcome measures, which collectively incorporate clinically relevant, sensitive and reproducible outputs, a single outcome measure incorporating all three qualities remains elusive.

\section{Keywords}

Charcot-Marie-Tooth disease

Outcome measures

Clinical trial

\section{Abbreviations}

CMT = Charcot-Marie-Tooth disease, HSN = Hereditary Sensory Neuropathy, $\mathrm{CMTNS}=$ CMT neuropathy score, $\mathrm{CMTES}=\mathrm{CMT}$ examination score, RNAI=RNA interference, INC=Inherited Neuropathy Consortium, 
SRM = standardised Response Mean (The SRM is an arbitrary measure of the responsiveness of a scale to clinical change. It is computed by dividing the mean score change by the standard deviation of the change. 


\section{Introduction}

Since the discovery of the $17 p$ duplication as the cause of CMT1A there has been significant progress made in both gene discovery for other forms of $\mathrm{CMT}$ and the development of therapies in pre-clinical models of CMT. Advances in Adeno Associated Viral (AAV) gene replacement therapy and antisense oligonucleotide (ASO)/RNAI biochemistry has meant that several types of CMT are now potentially amenable to therapy (Rossor et al., 2018; Zhao et al., 2018). Furthermore, the evolving importance of the unfolded protein response (UPR) and macrophage associated inflammation in several forms of CMT1 has led to the development of small molecule inhibitors of the UPR and inflammatory response which have shown promise in animal models of the disease (Das et al., 2015)'(Klein et al., 2015). The CMT field is therefore at a critical juncture where several promising therapies are ready to proceed to clinical trial, an essential step to be able to prove that a treatment does or does not work. Poor trial design, including the use of insensitive clinical outcome measures, will fail to answer this question. An effective drug may show no efficacy in a clinical trial with too short a duration and an insensitive outcome measure.

Similarly, multiple trials with inaccurate outcome measures may eventually result in a spuriously positive result. This review will highlight some of the challenges of preparing for clinical trials in CMT and provide an update on the work that has been conducted to date. This review will focus on preparing for randomised placebo controlled clinical trials for the common CMT subtypes such as CMT1A. In the case of rare CMT subtypes, there may be too few patients globally to power such a trial, in which case a cross over trial design in which each patient serves as their own control may be necessary. Furthermore, many of the outcome measure discussed relate to the typical progressive length dependent pattern of neuropathy seen in CMT and are not suitable for relapsing / remitting diseases such as Hereditary Neuropathy with Liability to Pressure Palsies. 


\section{Clinical trials in Charcot-Marie-Tooth disease: lessons learnt}

Following the publication of a single study reporting improvement of the C22 mouse model of CMT1A with ascorbic acid (Passage et al., 2004), six, placebo-controlled, randomised, clinical trials were performed across Europe, Australia and North America (Burns et al., 2009; Gess et al., 2015; Lewis et al., 2013; Micallef et al., 2009; Pareyson et al., 2011; Verhamme et al., 2009). These were the first large, multicentre clinical trials in CMT and were all negative for the primary outcome measure. Unfortunately, despite the considerable time and cost invested in these trials, it remains unanswered as to whether ascorbic acid is beneficial or not, as in hindsight, these trials were not powered to detect a meaningful response. For example, in two of the largest clinical trials, the primary outcome measure, the CMTNSv1, did not show any change in the placebo or ascorbic acid treated patients over the two-year duration of the trial (Lewis et al., 2013; Pareyson et al., 2011). Although an improvement with treatment in CMT1A is theoretically possible, by adulthood, most patients with CMT1A will have a degree of permanent axonal loss and so a more realistic aim of treatment would be to prevent or delay disease progression. In order to optimise future trial design, the necessity to identify novel and more sensitive outcome measures able to detect disease progression over the normal two-year duration of a trial was recognised as critical. In addition, an international collaborative effort was made to collect prospective natural history data on the many subtypes of CMT to facilitate future trial design.

\section{Natural history studies and CMT trial preparedness}

Due to the limited regenerative capacity of diseased peripheral nerves, the main aim of treatment in $\mathrm{CMT}$ is to prevent disease progression. It is therefore essential to have information on the rate of progression of a disease in order to understand what the expected effect size will be and ensure the trial is sufficiently powered in terms of subject recruitment. For example, in spinal muscular atrophy type 1, in which infants born with the disease die within several months of birth, the rate of progression is so 
rapid that only a small number of patients and trial duration are required to detect a clinically meaningful response. Contrast this with a slowly progressive disease such as CMT1A in which the CMTNS version 1 was unable to detect disease progression over two years (Pareyson et al., 2011; Shy et al., 2005). Quality of life studies have highlighted the need to develop therapies for both the rapidly and slowly progressive forms of CMT.

In order to facilitate future trial design, the inherited neuropathy Consortium (INC) (funded by NCATS/NINDS, MDA and CMTA) comprising centres from North America, Europe and Australia has been conducting a natural history study of children and adults with all types of CMT. More than 6,000 patients have been enrolled into the study, with annual assessments of disease severity as measured by the CMT examination score dating back up to nine years (Fridman et al., In press.). Although this is an open label prospective study, the data will provide information on the required duration of any future trial and the likely number of subjects required. In addition to natural history studies, the inherited neuropathy Consortium has a patient contact registry which allows patients who are not attending one of the recruiting centres to self-register ("RDCRN INC Contact Registry,"). This represents an important resource for quality of life and patient reported outcome measure development and for future trial recruitment, particularly for rare forms of CMT that may affect less than one hundred patients globally.

\section{Identifying suitable clinical outcome measures in CMT}

A good clinical outcome measure should have several properties; it should be sensitive to change, reproducible (little variation in the accuracy of the measurement) and clinically relevant. The latter point is hard to define but is essential when designing a primary outcome measure for a trial.

Outcome measures in Charcot-Marie-Tooth disease can be divided into one of five categories (Table 1);

1. Clinical outcome measures that incorporate a clinical assessment by a health professional 
2. Functional outcome measures in which the patient performs a series of tasks that assess their level of function

3. Patient reported outcome measures that select a number of responses that are deemed to be relevant to a patient's quality-of-life

4. Biomarkers of disease progression such as blood metabolite levels

5. Biomarkers of target engagement of specific therapies.

We will now discuss advances in outcome measures for CMT for each of these five categories.

\section{Clinical outcome measures in CMT}

The Charcot-Marie-Tooth neuropathy score version 1 was the first clinical outcome measures designed specifically for CMT and was modified from the total neuropathy score to measure impairment and progression in length dependent neuropathies (Cornblath et al., 1999; Shy et al., 2005). The score has several components including a patient's symptoms (motor and sensory), examination findings (both strength and sensory abnormalities to pinprick and vibration) and neurophysiology (radial sensory and ulnar motor amplitudes). An abbreviated version, the CMT examination score (CMTES) excludes the neurophysiology component. The first version of the CMTNS was an outcome measure in five of the initial six ascorbic acid in CMT1A trials. In response to the negative ascorbic acid trials, the CMTNS was further modified to increase the responsiveness (CMTNSv2) (Murphy et al., 2011).

More recently the CMTNSv2 has been re-evaluated in line with modern psychometrics such as item response theory. The Rasch analysis of the second version showed a clumping of impairments amongst patients with moderate severity (Sadjadi et al., 2014; Wang et al., 2017). This would suggest that the second version was insensitive for detecting small changes in progression between mild and moderate states or moderate and severe but was able to distinguish between mild and severely impaired patients. 
The score was therefore modified by applying differing weights to the various elements. The sensitivity of the Rasch modified version of the CMTNSv2 to detect change over time has recently been assessed as part of the INC natural history study, demonstrating a small but significant disease progression detectable over two years (Fridman et al., In press).

\section{ONLS}

The overall neuropathy limitation score, developed in 2005 , is a composite of two scores, one for upper limb function and the other for lower limb function based on a person's symptoms and gait analysis (Graham and Hughes, 2006). The ONLS was employed as a secondary outcome measure in several of the initial ascorbic acid in CMT1 trials and was shown to be insensitive to change over the duration of the trial. It was therefore rather surprising when it was selected as the primary outcome measure by the FDA for the recent phase 3 clinical trial of PXT3003 in CMT1A (Attarian et al., 2014). Despite its lack of sensitivity, the ONLS remains one of only a handful of outcome measures that have been approved for by the FDA for clinical trials in CMT.

\section{Functional outcome measures in CMT}

A functional outcome measure is similar to a clinical outcome measure, but instead of a patient being examined by a health professional, the patient is asked to perform a number of tasks that assess specific functions and are scored independently.

\section{CMTPedS}

One of the first functional outcome measures to be designed for CMT was the CMTPedS score (Burns et al., 2012). For CMT1A, the commonest subtype of CMT and for many of the other types of CMT, onset of the disease is in the first or second decades of life. Monitoring disease progression in childhood presents particular difficulties due to the inherent changes in an outcome measure as the child grows and 
develops. This is much less of a problem in adulthood where outcome measures stay relatively constant in control populations. A functional outcome measure in which a child performs a task has advantages over a regimented clinical outcome measure such as the CMTNSv2 where compliance with the clinical examination may be difficult (Murphy et al., 2011).

The CMT paediatric scale (CMTPeds) is an 11 item scale that measures seven functional domains including strength, dexterity, sensation, gait, balance, power and endurance producing a score of between 0 and 44 . The scale has been validated in large cohorts of children with CMT and age-specific normal scores calculated. Rasch analysis of the scale has shown it to be a good overall model fit with no evidence of clustering. Furthermore, there is now longitudinal data from the INC demonstrating the sensitivity of the CMTPeds for detecting disease progression in children. The score was able to detect progression of 1.864 points in 111 children with CMT1A over two years (Cornett et al., 2017). It was also able to detect progression of 2.26 points in nine patients with CMT 1B, 6.26 points in six patients with CMT2A and 3 points in seven patients with CMT4C. Nevertheless, using the CMTPedS for a two-year randomised double-blind parallel placebo-controlled trial in CMT1A would require a sample size of 86 children per arm to provide $80 \%$ power to detect a difference between the two groups of 1.8 points. This assumes no drop out and a treatment that can completely arrest the progression of the disease.

\section{CMT-FOM}

The Charcot-Marie-Tooth Functional Outcome Measure is a new performance based measure assessing functional ability in adults with CMT which has been designed to incorporate many of the items from the CMTPedS (Eichinger et al., 2018). It utilises a number of outcome measures including hand grip, anklefoot dorsiflexion and plantarflexion strength, nine-hole peg test to assess functional dexterity, balance beam, timed walk, stair climb and a timed up and go. The CMT-FOM is able to detect impairment in patients with CMT compared to controls. Its future use in clinical trials depends on the outcome of 
active longitudinal studies examining the psychometric properties of the score and its responsiveness to change.

\section{Myometry}

A retrospective study of the outcome measures employed in the Italian UK vitamin C trial identified myometric assessment of hand grip and foot dorsiflexion and the 9-hole peg test as more responsive fuctional outcome measures than the CMTNSv1 (Piscosquito et al., 2015). Nevertheless, these outcome measures still had limited sensitivity (SRM of $0.31,0.38$ and 0.28 respectively) and have not been evaluated in comparison with the Rasch modified CMTNSv2 and have not been included in any natural history study assessing other rare CMT variants.

\section{Patient reported outcome measures}

A meaningful, clinically important difference is a term used to describe a predetermined effect size that is deemed to be of significant benefit to a patient's quality of life. Clinical trials require this be predetermined for any outcome measure to be used as a primary endpoint. In order to identify clinically important outcome measures it is important to understand what aspects of CMT impact a patient's quality of life (Johnson et al., 2018, 2014). A survey of 407 patients with CMT questioned about 214 symptoms from 20 themes demonstrated that several items related to CMT significantly affect a patient's quality-of-life. It is therefore important that these specific themes be assessed in any primary outcome measure. Many of the issues identified relate to mobility, balance and distal motor and sensory loss that are incorporated in the CMTNSv2. Fatigue, pain and body image was also found to be important (Johnson et al., 2014).

To further ensure that a patient's quality of life can be directly measured in any clinical trial, the CMT health index has been developed (Johnson et al., 2018). This questionnaire contains 18 themes that 
identify factors related to Charcot-Marie-Tooth disease burden. The score has been shown to have high internal consistency and test retest reliability and is able to discriminate between patients in different disease states.

\section{Biomarkers of CMT disease progression and burden}

Efforts over the last 15-20 years have resulted in the development of several Charcot-Marie-Tooth disease specific clinical and functional outcome measures that are able to detect disease progression over 1-2 years. These scales are effective at discriminating between mild and severely affected patients (Sadjadi et al., 2014). Unfortunately, even for a highly sensitive outcome measure such as the CMTPedS, due to the intrasubject variability of the score, the number of participants required to adequately power a trial remains high(Cornett et al., 2017). This has led many researchers to try and identify biomarkers of disease progression that show less variability and are more sensitive to detecting change. As these are biomarkers, they are by definition not clinical or functional outcome measures, however the hope is that if shown to correlate strongly with clinical and functional outcome measures, they may be used as primary endpoints, enabling smaller sample sizes and the ability to detect a meaningful clinical response. Several disease biomarkers have been identified including MRI of muscle and nerve (Dortch et al., 2014; Kollmer et al., 2019; Morrow et al., 2016), blood biomarkers of axonal damage (Sandelius et al., 2018), skin biopsy for intra epidermal nerve fibre density (Fridman et al., 2019) and quantitative transcriptomics (Fledrich et al., 2017) and neurophysiology parameters (Bas et al., 2018).

\section{Muscle MRI fat fraction as a biomarker of disease progression in CMT.}

Intramuscular fat accumulation occurs as a result of muscle denervation from any neurogenic cause.

Quantitative skeletal muscle MRI in which the percentage of muscle that is occupied by fat is calculated, has been shown to be a sensitive and reproducible method for quantifying the degree of disease burden in CMT 1A and hereditary sensory neuropathy type 1 (Kugathasan et al., 2019; Morrow et al., 2016). 
Using the three-point Dixon MRI of skeletal muscle at calf level, an increase in muscle fat fraction of $1.2 \%(95 \% \mathrm{Cl} 0.5-1.9, \mathrm{p}=0.002)$ was detectable in 20 patients with $\mathrm{CMT} 1 \mathrm{~A}$ over one year showing it to be a highly responsive measure. If one were to extrapolate the data from this study, for a hypothetical treatment trial in CMT1A powered to detect a 50\% reduction in disease progression over a one-year period with $80 \%$ power at the $p<0.05$ significance level, with calf muscle MRI fat fraction as the primary outcome measure, the number of patients required in both the treatment and placebo arms would be 93 compared with 7700 with the CMTNSv1 as an outcome measure (Morrow et al., 2016). For the CMTNSv2, the number of patients required is likely to be fewer than the CMTNSv1. The responsiveness of muscle MRI can be further improved from an SRM of 1.04 to 2.19 by selecting patients with $>10 \%$ calf fat fraction at baseline (Morrow et al., 2018).

Muscle fat fraction quantification in CMT1A has also been shown to be a reproducible method across two different sites further supporting its use in multicentre international clinical trials (Morrow et al., 2018). One of the main criticisms directed against muscle fat fraction as an outcome measure is that is not clinically relevant. Although this is true, it has been shown to correlate with the CMTESv2 and the physical function domain of the SF36 Quality of Life Score (Morrow et al., 2016). Although muscle MRI is a sensitive and reproducible clinical outcome measure, it is expensive and time consuming which may limit its use in very large international clinical trials

\section{Blood biomarkers of CMT}

Blood is easily accessible and obtainable at multiple time points and therefore any blood test that can detect disease progression in CMT is attractive for future clinical trial design. A number of blood biomarkers of peripheral neuropathy have been analysed for their suitability as outcome measures including GFAP (Notturno et al., 2009), Transmembrane Protease Serine 5 (Wang et al., 2019), neurofilament heavy chain (Rossor et al., 2016) and more recently neurofilament light chain (Sandelius 
et al., 2018). Of these, neurofilament light chain shows the greatest promise as a biomarker of axonal damage in CMT. Neurofilaments are the major cytoskeletal proteins of both the central and peripheral nervous system and comprise a lattice made up of neuro neurofilament heavy, medium and light chains. Damage to either the central or peripheral nervous system will lead to release of these proteins into the cerebral spinal fluid and systemic circulation. Much of the work demonstrating the suitability of neurofilament light chain as a biomarker of disease has centred on its use in central nervous system diseases such as multiple sclerosis and dementia (Disanto et al., 2017; Rohrer et al., 2016). More recently, plasma neurofilament light chain has been shown to be raised in Charcot-Marie-Tooth disease where it also correlates with disease severity as measured by the CMT examination score (Sandelius et al., 2018). Plasma NFL is also elevated in some inflammatory neuropathies including CIDP (Mariotto et al., 2018; van Lieverloo et al., 2019) and vasculitis (Bischof et al., 2018). Encouragingly, plasma neurofilament light chain is also elevated in mouse models of Charcot-Marie-Tooth disease and correlates with a clinically significant response to treatment. For example, in mouse models of CMT1X and $\mathrm{CMT4C}$, viral gene replacement therapy led to a clinical improvement in affected mice which correlated with a fall in plasma neurofilament light chain concentration (Kagiava et al., 2019; Schiza et al., 2019). Further studies are ongoing to determine the relationship of plasma neurofilament light chain over time in patients with $\mathrm{CMT}$ and its correlation with other biomarkers and outcome measures.

\section{Other biomarkers of CMT disease progression.}

In addition to MRI and blood biomarkers of disease progression, a combined study of RNA expression in CMT1A rat and human skin biopsies demonstrated six RNA transcripts elevated in CMT1A that were shown to change over time and correlate with disease progression (Fledrich et al., 2017). The clinical and biological relevance of these transcripts is uncertain. Additional attempts to identify new 
neurophysiological biomarkers such as motor unit estimation (MUNE) have also shown promise as biomarkers of disease progression in CMT(Bas et al., 2018).

\section{Biomarkers of target engagement of specific therapies}

In addition to developing biomarkers of disease progression it is also important to develop biomarkers of target engagement specific for individual therapies. This is important as if you are able to show target engagement with no clinical effect then one is able to ascertain that the therapeutic strategy is unsuccessful. Similarly, if there is no target engagement and the trial is negative then further work may need to be done in improving drug bioavailability or trial design rather than adopting an alternative strategy.

\section{Biomarkers of target engagement in CMT1A}

CMT1A results from a duplication of the short arm of chromosome 17 containing the PMP22 gene. Therapeutic strategies in CMT1A have therefore focused on reducing PMP22 transcription (Zhao et al., 2018). One of the most promising biomarkers of therapeutic target engagement in this area has been the ability to reliably quantify PMP22 transcript levels in the skin biopsies of patients (Katona et al., 2009; Li et al., 2005; Svaren et al., 2019). Skin biopsies contain a small number of dermal myelinated nerve fibres from which quantification of $P M P 22$ transcript levels from Schwann cells is possible.

Quantification of PMP22 transcript levels in skin biopsies is not straightforward as patients with severe CMT1A have extensive nerve degeneration and a reduced number of dermal myelinated fibres and Schwann cells. For this reason, simple quantification of $P M P 22$ transcript levels in patients with CMT1A shows no correlation with disease activity or status relative to controls. One of the main challenges has been the ability to normalise PMP22 transcript levels to Schwann cell specific transcripts. This in turn is complex as many Schwann cell specific genes change dramatically after peripheral nerve injury. In work arising from rodents and human patients with CMT1A, the Schwann cell specific transcript, GLDN in skin 
biopsies was shown to be a reliable marker of Schwann cell expression that was not dramatically altered by peripheral nerve injury (Svaren et al., 2019). PMP22 transcript levels when corrected to GLDN were significantly increased in the skin biopsies of patients with CMT1A compared to controls and are a promising biomarker of target engagement in any future trial involving a therapy that aims to reduce PMP22 transcription (Svaren et al., 2019).

\section{Biomarkers of target engagement in HSN1}

Hereditary sensory neuropathy type I is due to missense mutations in the genes SPTLC1 and SPTLC2, which code for the first two of three subunits of the enzyme serine palmitoyl transferase (SPT). Mutations in this enzyme lead to the production of toxic deoxysphingolipids that are thought to drive sensory and motor nerve degeneration. Measurement of these toxic deoxysphingolipids represents a biomarker of target engagement for serine replacement therapy which aims to reduce their production. In a small trial of 18 patients with HSN1, plasma deoxysphingolpid concentrations were significantly reduced in patients treated with serine compared to placebo (Fridman et al., 2019). Although this suggested good target engagement, the trial failed to achieve its primary outcome measure; a predetermined improvement of one-point in the CMTNSv2.

\section{Summary}

In the last 15 years there has been considerable progress in preparing for clinical trials in CMT. There are large and ongoing natural history studies of both common and rare forms of CMT that will provide important information to inform and power clinical trial design. In addition, there are now a number of clinical and functional outcome measures for both adult and paediatric CMT patients and ongoing studies to examine the cross-sectional correlation of these novel outcome measures. 
There are now promising biomarkers of disease activity and burden in the form of muscle MRI and plasma neurofilament light chain and biomarkers of target engagement for the most common subtype of CMT, CMT1A. Despite these advances in trial outcome measures, the most recent large clinical trial of PXT3003 in CMT1A involved the use of the overall neuropathy limitation score (ONLS), an outcome measure designed in 2005 for patients with CIDP and for which natural history data from the ascorbic acid in CMT1A trials shows it to be insensitive for detecting disease progression over 24 months (Gess et al., 2015). It would be concerning if this outcome measure were to become the gold standard for future trials in Charcot-Marie-Tooth disease. Charcot-Marie-Tooth disease is rare and patients are a finite resource. As a community we have a responsibility to be selective in the number of clinical trials into which we recruit patients. It is imperative that we employ sensitive outcome measures and biomarkers that are able to detect a clinically significant effect and avoid undertaking expensive and timeconsuming trials using outcome measures that are doomed to fail.

\section{Acknowledgements}

MMR is grateful to the Medical Research Council (MRC), MRC Centre grant (G0601943), and the National Institutes of Neurological Diseases and Stroke and office of Rare Diseases (U54NS065712) for their support. This research was also supported by the National Institute for Health Research University College London Hospitals Biomedical Research Centre.

\section{References}

Attarian, S., Vallat, J.-M., Magy, L., Funalot, B., Gonnaud, P.-M., Lacour, A., Péréon, Y., Dubourg, O., Pouget, J., Micallef, J., Franques, J., Lefebvre, M.-N., Ghorab, K., Al-Moussawi, M., Tiffreau, V., Preudhomme, M., Magot, A., Leclair-Visonneau, L., Stojkovic, T., Bossi, L., Lehert, P., Gilbert, W., Bertrand, V., Mandel, J., Milet, A., Hajj, R., Boudiaf, L., Scart-Grès, C., Nabirotchkin, S., Guedj, M., Chumakov, I., Cohen, D., 2014. An exploratory randomised double-blind and placebo-controlled 
phase 2 study of a combination of baclofen, naltrexone and sorbitol (PXT3003) in patients with Charcot-Marie-Tooth disease type 1A. Orphanet J. Rare Dis. 9, 199. https://doi.org/10.1186/s13023-014-0199-0

Bas, J., Delmont, E., Fatehi, F., Salort-Campana, E., Verschueren, A., Pouget, J., Lefebvre, M.-N.N., Grapperon, A.-M.M., Attarian, S., 2018. Motor unit number index correlates with disability in Charcot-Marie-Tooth disease. Clin. Neurophysiol. 129, 1390-1396. https://doi.org/10.1016/j.clinph.2018.04.359

Bischof, A., Manigold, T., Barro, C., Heijnen, I., Berger, C.T., Derfuss, T., Kuhle, J., Daikeler, T., 2018. Serum neurofilament light chain: a biomarker of neuronal injury in vasculitic neuropathy. Ann. Rheum. Dis. 77, 1093-1094. https://doi.org/10.1136/annrheumdis-2017-212045

Burns, J., Ouvrier, R., Estilow, T., Shy, R., Laurá, M., Pallant, J.F., Lek, M., Muntoni, F., Reilly, M.M., Pareyson, D., Acsadi, G., Shy, M.E., Finkel, R.S., 2012. Validation of the Charcot-Marie-Tooth disease pediatric scale as an outcome measure of disability. Ann. Neurol. 71, 642-652. https://doi.org/10.1002/ana.23572

Burns, J., Ouvrier, R.A., Yiu, E.M., Joseph, P.D., Kornberg, A.J., Fahey, M.C., Ryan, M.M., 2009. Ascorbic acid for Charcot-Marie-Tooth disease type $1 \mathrm{~A}$ in children: a randomised, double-blind, placebocontrolled, safety and efficacy trial. Lancet. Neurol. 8, 537-44. https://doi.org/10.1016/S14744422(09)70108-5

Cornblath, D.R., Chaudhry, V., Carter, K., Lee, D., Seysedadr, M., Miernicki, M., Joh, T., 1999. Total neuropathy score: Validation and reliability study. Neurology 53, 1660-1660. https://doi.org/10.1212/WNL.53.8.1660

Cornett, K.M.D., Menezes, M.P., Shy, R.R., Moroni, I., Pagliano, E., Pareyson, D., Estilow, T., Yum, S.W., 
Bhandari, T., Muntoni, F., Laura, M., Reilly, M.M., Finkel, R.S., Eichinger, K.J., Herrmann, D.N., Bray, P., Halaki, M., Shy, M.E., Burns, J., CMTPedS Study Group, 2017. Natural history of Charcot-MarieTooth disease during childhood. Ann. Neurol. 82, 353-359. https://doi.org/10.1002/ana.25009

Das, I., Krzyzosiak, A., Schneider, K., Wrabetz, L., D’Antonio, M., Barry, N., Sigurdardottir, A., Bertolotti, A., 2015. Preventing proteostasis diseases by selective inhibition of a phosphatase regulatory subunit. Science 348, 239-42. https://doi.org/10.1126/science.aaa4484

Disanto, G., Barro, C., Benkert, P., Naegelin, Y., Schädelin, S., Giardiello, A., Zecca, C., Blennow, K., Zetterberg, H., Leppert, D., Kappos, L., Gobbi, C., Kuhle, J., Swiss Multiple Sclerosis Cohort Study Group, 2017. Serum Neurofilament light: A biomarker of neuronal damage in multiple sclerosis. Ann. Neurol. 81, 857-870. https://doi.org/10.1002/ana.24954

Dortch, R.D., Dethrage, L.M., Gore, J.C., Smith, S.A., Li, J., 2014. Proximal nerve magnetization transfer MRI relates to disability in Charcot-Marie-Tooth diseases. Neurology 83, 1545-53. https://doi.org/10.1212/WNL.0000000000000919

Eichinger, K., Burns, J., Cornett, K., Bacon, C., Shepherd, M.L., Mountain, J., Sowden, J., Shy, R., Shy, M.E., Herrmann, D.N., 2018. The Charcot-Marie-Tooth Functional Outcome Measure (CMT-FOM). Neurology 91, e1381-e1384. https://doi.org/10.1212/WNL.0000000000006323

Fledrich, R., Mannil, M., Leha, A., Ehbrecht, C., Solari, A., Pelayo-Negro, A.L., Berciano, J., SchlotterWeigel, B., Schnizer, T.J., Prukop, T., Garcia-Angarita, N., Czesnik, D., Haberlová, J., Mazanec, R., Paulus, W., Beissbarth, T., Walter, M.C., TRIAAL, C.-, Hogrel, J.-Y., Dubourg, O., Schenone, A., Baets, J., Jonghe, P. De, Shy, M.E., Horvath, R., Pareyson, D., Seeman, P., Young, P., Sereda, M.W., 2017. Biomarkers predict outcome in Charcot-Marie-Tooth disease 1A. J. Neurol. Neurosurg. Psychiatry 88, 941-952. https://doi.org/10.1136/JNNP-2017-315721 
Fridman, V., Sillau, S., Acsardi, G., n.d. A longitudinal study of CMT1A using Rasch analysis based CMT neuropathy and examiantion scores. Ann. Neurol.

Fridman, V., Suriyanarayanan, S., Novak, P., David, W., Macklin, E.A., McKenna-Yasek, D., Walsh, K., AzizBose, R., Oaklander, A.L., Brown, R., Hornemann, T., Eichler, F., 2019. Randomized trial of I-serine in patients with hereditary sensory and autonomic neuropathy type 1. Neurology 92, e359-e370. https://doi.org/10.1212/WNL.0000000000006811

Gess, B., Baets, J., De Jonghe, P., Reilly, M.M., Pareyson, D., Young, P., 2015. Ascorbic acid for the treatment of Charcot-Marie-Tooth disease. Cochrane database Syst. Rev. 12, CD011952. https://doi.org/10.1002/14651858.CD011952

Graham, R.C., Hughes, R.A.C., 2006. A modified peripheral neuropathy scale: The Overall Neuropathy Limitations Scale. J. Neurol. Neurosurg. Psychiatry 77, 973-976. https://doi.org/10.1136/jnnp.2005.081547

Johnson, N.E., Heatwole, C., Creigh, P., McDermott, M.P., Dilek, N., Hung, M., Bounsanga, J., Tang, W., Shy, M.E., Herrmann, D.N., 2018. The Charcot-Marie-Tooth Health Index: Evaluation of a PatientReported Outcome. Ann. Neurol. 84, 225-233. https://doi.org/10.1002/ana.25282

Johnson, N.E., Heatwole, C.R., Dilek, N., Sowden, J., Kirk, C.A., Shereff, D., Shy, M.E., Herrmann, D.N., 2014. Quality-of-life in Charcot-Marie-Tooth disease: The patient's perspective. Neuromuscul. Disord. 24, 1018-1023. https://doi.org/10.1016/j.nmd.2014.06.433

Kagiava, A., Richter, J., Tryfonos, C., Karaiskos, C., Heslegrave, A.J., Sargiannidou, I., Rossor, A.M., Zetterberg, H., Reilly, M.M., Christodoulou, C., Kleopa, K.A., 2019. Gene replacement therapy after neuropathy onset provides therapeutic benefit in a model of CMT1X. Hum. Mol. Genet. https://doi.org/10.1093/hmg/ddz199 
Katona, I., Wu, X., Feely, S.M.E., Sottile, S., Siskind, C.E., Miller, L.J., Shy, M.E., Li, J., 2009. PMP22

expression in dermal nerve myelin from patients with CMT1A. Brain 132, 1734-40. https://doi.org/10.1093/brain/awp113

Klein, D., Patzkó, Á., Schreiber, D., van Hauwermeiren, A., Baier, M., Groh, J., West, B.L., Martini, R., 2015. Targeting the colony stimulating factor 1 receptor alleviates two forms of Charcot-MarieTooth disease in mice. Brain 138, 3193-205. https://doi.org/10.1093/brain/awv240

Kollmer, J., Hilgenfeld, T., Ziegler, A., Saffari, A., Sam, G., Hayes, J.M., Pietsch, A., Jost, M., Heiland, S., Bendszus, M., Wick, W., Weiler, M., 2019. Quantitative MR neurography biomarkers in 5q-linked spinal muscular atrophy. Neurology 93, e653-e664. https://doi.org/10.1212/WNL.0000000000007945

Kugathasan, U., Evans, M.R.B., Morrow, J.M., Sinclair, C.D.J., Thornton, J.S., Yousry, T.A., Hornemann, T., Suriyanarayanan, S., Owusu-Ansah, K., Lauria, G., Lombardi, R., Polke, J.M., Wilson, E., Bennett, D.L.H., Houlden, H., Hanna, M.G., Blake, J.C., Laura, M., Reilly, M.M., 2019. Development of MRC Centre MRI calf muscle fat fraction protocol as a sensitive outcome measure in Hereditary Sensory Neuropathy Type 1. J. Neurol. Neurosurg. Psychiatry jnnp-2018-320198. https://doi.org/10.1136/jnnp-2018-320198

Lewis, R.A., McDermott, M.P., Herrmann, D.N., Hoke, A., Clawson, L.L., Siskind, C., Feely, S.M.E., Miller, L.J., Barohn, R.J., Smith, P., Luebbe, E., Wu, X., Shy, M.E., 2013. High-dosage ascorbic acid treatment in Charcot-Marie-Tooth disease type 1A: results of a randomized, double-masked, controlled trial. JAMA Neurol. 70, 981-7. https://doi.org/10.1001/jamaneurol.2013.3178

Li, J., Bai, Y., Ghandour, K., Qin, P., Grandis, M., Trostinskaia, A., lanakova, E., Wu, X., Schenone, A., Vallat, J.-M., Kupsky, W.J., Hatfield, J., Shy, M.E., 2005. Skin biopsies in myelin-related 
neuropathies: bringing molecular pathology to the bedside. Brain 128, 1168-77.

https://doi.org/10.1093/brain/awh483

Mariotto, S., Farinazzo, A., Magliozzi, R., Alberti, D., Monaco, S., Ferrari, S., 2018. Serum and cerebrospinal neurofilament light chain levels in patients with acquired peripheral neuropathies. J. Peripher. Nerv. Syst. 23, 174-177. https://doi.org/10.1111/jns.12279

Micallef, J., Attarian, S., Dubourg, O., Gonnaud, P.-M., Hogrel, J.-Y., Stojkovic, T., Bernard, R., Jouve, E., Pitel, S., Vacherot, F., Remec, J.-F., Jomir, L., Azabou, E., Al-Moussawi, M., Lefebvre, M.-N., Attolini, L., Yaici, S., Tanesse, D., Fontes, M., Pouget, J., Blin, O., 2009. Effect of ascorbic acid in patients with Charcot-Marie-Tooth disease type 1A: a multicentre, randomised, double-blind, placebo-controlled trial. Lancet. Neurol. 8, 1103-10. https://doi.org/10.1016/S1474-4422(09)70260-1

Morrow, J.M., Evans, M.R.B., Grider, T., Sinclair, C.D.J., Thedens, D., Shah, S., Yousry, T.A., Hanna, M.G., Nopoulos, P., Thornton, J.S., Shy, M.E., Reilly, M.M., 2018. Validation of MRC Centre MRI calf muscle fat fraction protocol as an outcome measure in CMT1A. Neurology 91, e1125-e1129. https://doi.org/10.1212/WNL.0000000000006214

Morrow, J.M., Sinclair, C.D.J., Fischmann, A., Machado, P.M., Reilly, M.M., Yousry, T.A., Thornton, J.S., Hanna, M.G., 2016. MRI biomarker assessment of neuromuscular disease progression: a prospective observational cohort study. Lancet. Neurol. 15, 65-77. https://doi.org/10.1016/S1474$4422(15) 00242-2$

Murphy, S.M., Herrmann, D.N., McDermott, M.P., Scherer, S.S., Shy, M.E., Reilly, M.M., Pareyson, D., 2011. Reliability of the CMT neuropathy score (second version) in Charcot-Marie-Tooth disease. J. Peripher. Nerv. Syst. 16, 191-8. https://doi.org/10.1111/j.1529-8027.2011.00350.x

Notturno, F., Capasso, M., Delauretis, A., Carpo, M., Uncini, A., 2009. Glial fibrillary acidic protein as a 
marker of axonal damage in chronic neuropathies. Muscle Nerve 40, 50-54.

https://doi.org/10.1002/mus.21323

Pareyson, D., Reilly, M.M., Schenone, A., Fabrizi, G.M., Cavallaro, T., Santoro, L., Vita, G., Quattrone, A., Padua, L., Gemignani, F., Visioli, F., Laurà, M., Radice, D., Calabrese, D., Hughes, R.A.C., Solari, A., 2011. Ascorbic acid in Charcot-Marie-Tooth disease type 1A (CMT-TRIAAL and CMT-TRAUK): a double-blind randomised trial. Lancet. Neurol. 10, 320-8. https://doi.org/10.1016/S1474$4422(11) 70025-4$

Passage, E., Norreel, J.C., Noack-Fraissignes, P., Sanguedolce, V., Pizant, J., Thirion, X., Robaglia-Schlupp, A., Pellissier, J.F., Fontés, M., 2004. Ascorbic acid treatment corrects the phenotype of a mouse model of Charcot-Marie-Tooth disease. Nat. Med. 10, 396-401. https://doi.org/10.1038/nm1023

Piscosquito, G., Reilly, M.M., Schenone, A., Fabrizi, G.M., Cavallaro, T., Santoro, L., Manganelli, F., Vita, G., Quattrone, A., Padua, L., Gemignani, F., Visioli, F., Laurà, M., Calabrese, D., Hughes, R.A.C., Radice, D., Solari, A., Pareyson, D., 2015. Responsiveness of clinical outcome measures in CharcotMarie-Tooth disease. Eur. J. Neurol. 22, 1556-63. https://doi.org/10.1111/ene.12783

RDCRN INC Contact Registry [WWW Document], n.d. URL https://www.rarediseasesnetwork.org/cms/inc/registry

Rohrer, J.D., Woollacott, I.O.C., Dick, K.M., Brotherhood, E., Gordon, E., Fellows, A., Toombs, J., Druyeh, R., Cardoso, M.J., Ourselin, S., Nicholas, J.M., Norgren, N., Mead, S., Andreasson, U., Blennow, K., Schott, J.M., Fox, N.C., Warren, J.D., Zetterberg, H., 2016. Serum neurofilament light chain protein is a measure of disease intensity in frontotemporal dementia. Neurology 87, 1329-1336. https://doi.org/10.1212/WNL.0000000000003154

Rossor, A.M., Liu, C.-H., Petzold, A., Malaspina, A., Laura, M., Greensmith, L., Reilly, M.M., 2016. Plasma 
neurofilament heavy chain is not a useful biomarker in Charcot-Marie-Tooth disease. Muscle and Nerve 53. https://doi.org/10.1002/mus.25124

Rossor, A.M., Reilly, M.M., Sleigh, J.N., 2018. Antisense oligonucleotides and other genetic therapies made simple. Pract. Neurol. 18. https://doi.org/10.1136/practneurol-2017-001764

Sadjadi, R., Reilly, M.M., Shy, M.E., Pareyson, D., Laura, M., Murphy, S., Feely, S.M.E., Grider, T., Bacon, C., Piscosquito, G., Calabrese, D., Burns, T.M., 2014. Psychometrics evaluation of Charcot-MarieTooth Neuropathy Score (CMTNSv2) second version, using Rasch analysis. J. Peripher. Nerv. Syst. 19, 192-6. https://doi.org/10.1111/jns.12084

Sandelius, Å., Zetterberg, H., Blennow, K., Adiutori, R., Malaspina, A., Laura, M., Reilly, M.M., Rossor, A.M., 2018. Plasma neurofilament light chain concentration in the inherited peripheral neuropathies. Neurology 90, e518-e524. https://doi.org/10.1212/WNL.0000000000004932

Schiza, N., Georgiou, E., Kagiava, A., Médard, J.-J., Richter, J., Tryfonos, C., Sargiannidou, I., Heslegrave, A.J., Rossor, A.M., Zetterberg, H., Reilly, M.M., Christodoulou, C., Chrast, R., Kleopa, K.A., 2019. Gene replacement therapy in a model of Charcot-Marie-Tooth 4 C neuropathy. Brain 142, 12271241. https://doi.org/10.1093/brain/awz064

Shy, M.E., Blake, J., Krajewski, K., Fuerst, D.R., Laura, M., Hahn, A.F., Li, J., Lewis, R.A., Reilly, M., 2005. Reliability and validity of the CMT neuropathy score as a measure of disability. Neurology 64, 1209-14. https://doi.org/10.1212/01.WNL.0000156517.00615.A3

Svaren, J., Moran, J.J., Wu, X., Zuccarino, R., Bacon, C., Bai, Y., Ramesh, R., Gutmann, L., Anderson, D.M., Pavelec, D., Shy, M.E., 2019. Schwann cell transcript biomarkers for hereditary neuropathy skin biopsies. Ann. Neurol. 85, 887-898. https://doi.org/10.1002/ana.25480

van Lieverloo, G.G.A., Wieske, L., Verhamme, C., Vrancken, A.F.J., van Doorn, P.A., Michalak, Z., Barro, 
C., van Schaik, I.N., Kuhle, J., Eftimov, F., 2019. Serum neurofilament light chain in chronic inflammatory demyelinating polyneuropathy. J. Peripher. Nerv. Syst. 24, 187-194. https://doi.org/10.1111/jns.12319

Verhamme, C., de Haan, R.J., Vermeulen, M., Baas, F., de Visser, M., van Schaik, I.N., 2009. Oral high dose ascorbic acid treatment for one year in young CMT1A patients: a randomised, double-blind, placebo-controlled phase II trial. BMC Med. 7, 70. https://doi.org/10.1186/1741-7015-7-70

Wang, H., Davison, M., Wang, K., Xia, T.-H., Kramer, M., Call, K., Luo, J., Wu, X., Zuccarino, R., Bacon, C., Bai, Y., Moran, J.J., Gutmann, L., Feely, S.M.E., Grider, T., Rossor, A.M., Reilly, M.M., Svaren, J., Shy, M.E., 2019. Transmembrane Protease Serine 5: A Novel Schwann Cell Plasma Biomarker for CMT1A Running Title: Novel CMT1A Plasma Biomarker. Ann. Clin. Transl. Neurol. In press.

Wang, W., Guedj, M., Bertrand, V., Foucquier, J., Jouve, E., Commenges, D., Proust-Lima, C., Murphy, N.P., Blin, O., Magy, L., Cohen, D., Attarian, S., 2017. A Rasch Analysis of the Charcot-Marie-Tooth Neuropathy Score (CMTNS) in a Cohort of Charcot-Marie-Tooth Type 1A Patients. PLoS One 12, e0169878. https://doi.org/10.1371/journal.pone.0169878

Zhao, H.T., Damle, S., Ikeda-Lee, K., Kuntz, S., Li, J., Mohan, A., Kim, A., Hung, G., Scheideler, M.A., Scherer, S.S., Svaren, J., Swayze, E.E., Kordasiewicz, H.B., 2018. PMP22 antisense oligonucleotides reverse Charcot-Marie-Tooth disease type 1A features in rodent models. J. Clin. Invest. 128, 359368. https://doi.org/10.1172/JCI96499 


\begin{tabular}{|l|l|l|}
\hline $\begin{array}{l}\text { Category of Outcome } \\
\text { Measure }\end{array}$ & Outcome measure & $\begin{array}{l}\mathrm{SRM}^{*} \\
(\mathrm{months})\end{array}$ \\
\hline Clinical & CMTNSv1 & $0.13(24)$ \\
& CMTNSv2 & $\mathrm{n} / \mathrm{a}$ \\
& Rasch modified CMTNS & $\mathrm{n} / \mathrm{a}$ \\
& Hand grip myometry & $-0.31(24)$ \\
& Ankle dorsiflexion myometry & $-0.38(24)$ \\
& ONLS & $0.15(24$ \\
\hline Functional & 9-hole peg test & $0.28(24)$ \\
& CMTPedS & $0.43(24)$ \\
& CMT-FOM & $\mathrm{n} / \mathrm{a}$ \\
\hline Patient Reported & SF-36 (physical functioning domain) & $-0.10(24)$ \\
& CMT health index & $\mathrm{n} / \mathrm{a}$ \\
\hline Biomarkers of disease & - Muscle Fat Fraction MRI & $1.04(12)$ \\
progression & - -If baseline $>10 \%$ fat fraction & $2.19(12)$ \\
& -Plasma neurofilament light chain & $\mathrm{n} / \mathrm{a}$ \\
\hline Biomarkers of target & -PMP22 transcript levels (CMT1A) & $\mathrm{n} / \mathrm{a}$ \\
engagement & -Plasma deoxysphingolipid & $\mathrm{n} / \mathrm{a}$ \\
\hline & concentration (HSN1) & \\
\hline
\end{tabular}

Table 1. A summary of some of the currently available outcome measures for clinical trials in CMT. * refers only to patients with CMT1A. $n / a=$ data not available. 